\title{
Tumor Size-driven Dose of Intraoperative Radiotherapy for Breast Cancer: 18 Gy Versus 21 Gy
}

\author{
ELISABETTA BONZANO ${ }^{1}$, LILIANA BELGIOIA ${ }^{1}$, PIERO FREGATTI ${ }^{2}$, \\ DANIELE FRIEDMAN ${ }^{2}$, STEFANO AGOSTINELLI ${ }^{3}$, FRANCESCA CAVAGNETTO ${ }^{3}$, \\ MONICA BEVEGNI $^{3}$, RENZO CORVÒ $^{1 *}$ and MARINA GUENZI ${ }^{1 *}$ \\ Departments of ${ }^{1}$ Radiation Oncology, ${ }^{2}$ Surgery and ${ }^{3}$ Medical Physics, \\ IRCCS Policlinico San Martino and University, Genoa, Italy
}

\begin{abstract}
Aim: To test whether a reduced total single dose of $18 \mathrm{~Gy}$ of intraoperative radiotherapy with electrons (IORT) may be tailored to safely treat patients in comparison with the standard dose of 21 Gy. (NCT01276938). Patients and Methods: From October 2009 to December 2011, 199 females affected by breast cancer were treated with conservative surgery and IORT with two different exclusive doses, 18 or 21 Gy. Results: The median follow-up was 91 months (16-104 months). Sixty-five patients (pTla $\backslash$, pNO\mic, pMx, G1-G3) received 18 Gy and 134 patients (pT1c 2 , pNO\mic, pMx, G1-G3) received 21 Gy. No significant difference in local recurrence-free survival or overall survival was detected in the 18 Gy-treated arm versus that treated with 21 Gy: $96.9 \%$ vs. 96.3\%, $p=0.72$, and $96.9 \%$ vs. $95.5 \%, p=0.82$, respectively at 5 years. Conclusion: The lower dose of 18 Gy achieved excellent results in terms of local toxicity and local control in early breast cancer.
\end{abstract}

Breast-conserving surgery followed by whole-breast external radiation therapy (WBI) is usually the standard treatment for early breast cancer (1). Several clinical trials have demonstrated that about $90 \%$ of local recurrences after conservative breast surgery appear in the same area of the previous tumor (index quadrant) $(2,3)$.

According to this evidence, different trials on accelerated partial breast irradiation (APBI) were conducted with

*These Authors contributed equally to this study.

Correspondence to: Elisabetta Bonzano, Department of Radiation Oncology, IRCCS Policlinico San Martino and University, Largo R. Benzi 10, 16132 Genoa, Italy. Mobile: +39 3381976745, e-mail: elisabettabonzano@gmail.com

Key Words: Intraoperative radiation therapy, early-stage breast cancer, dose. promising results (4-6). Several methods for APBI can be used: interstitial and endocavitary (Mammosite) brachytherapy, 3Dconformal external radiotherapy, and intraoperative radiotherapy (IORT) with photon or electron beam (7).

IORT can be used either as a single exclusive dose in patients with early breast cancer patients or added as a boost on the tumor bed in high-risk cases; two large prospective randomized trials using breast IORT, TARGIT-A (Targeted Intraoperative Radiotherapy) and ELIOT (electron IORT) (8, 9), compared with IORT (as a single dose or as a boost) versus external radiotherapy for early breast cancer and demonstrated a low local recurrence rate and a good survival rate, in both arms (10).

Performed in theatre during conservative surgery, exclusive IORT offers multiple advantages: Firstly, it allows reduction of hospital visits for the patient, but above all, it leads to a better delineation of the tumor bed and subclinical disease $(8,11)$. Furthermore, the greatest advantage of the IORT treatment protocol derives from reduction of normal tissue toxicity by reducing radiation to the skin and the adjacent normal breast gland and healthy tissue (12). Moreover, IORT has a potential advantage in efficacy related to overall survival due to reduced cardiopulmonary radiation doses (13).

Regarding radiobiological issues, delivering a high exclusive single dose, such as $21 \mathrm{~Gy}$, avoids the problems of cancer cell repopulation and repair by increasing the tumorkill effect of surgery and radiation therapy. This achieves early elimination of subclinical disease and avoids tumor growth between the time of surgery and the beginning of adjuvant fractionated radiotherapy (11). As a matter of fact, a single $21 \mathrm{~Gy}$ dose is considered to be biologically equivalent to 1.5-2.5 times higher the WBI (14).

The aim of this study was to evaluate toxicity in patients with breast cancer treated with two different doses of IORT to test whether a reduced single dose (18 Gy) of IORT may be tailored to safely treat patients with selected early breast cancer in comparison with the standard dose of $21 \mathrm{~Gy}$. 


\section{Patients and Methods}

From October 2009 to December 2011, 199 patient candidates for IORT were included in a mono-institutional interventional study approved by the Ethics Committee (NCT01276938).

The median age at diagnosis was 67 (range=45-85) years Females eligible for breast-conserving surgery, with biopsy-proven invasive carcinoma (ductal, cribriform, tubular, apocrine, mucinous) and with a primary mass of less than $2.5 \mathrm{~cm}$, negative margin, intraductal component $<25 \%$ and no previous history of cancer, were included in this study (Table I).

According to the major tumor diameter, evaluated with frozen section examination, patients underwent one of two different doses: $<1 \mathrm{~cm}$ : a single dose of $18 \mathrm{~Gy} ; 1-<2.5 \mathrm{~cm}$ : a single dose of $21 \mathrm{~Gy}$. Thence the prescription single radiation dose was driven by tumor size.

According to the common linear quadratic formula $(15,16)$, considering for breast tumor a radiosensitivity $\alpha / \beta$ value of $4 \mathrm{~Gy}$, $21 \mathrm{~Gy}$ in one fraction would be biologically equivalent to $70 \mathrm{~Gy}$ in 35 fractions, while $18 \mathrm{~Gy}$ in one fraction is equivalent to $60 \mathrm{~Gy}$ in 30 fractions.

After wide local excision, sentinel lymph node dissection, and surgical positioning of the appropriately-sized applicator on the tumor bed, a single dose of $18 \mathrm{~Gy}$ or $21 \mathrm{~Gy}$ was given using LIAC, a mobile linear accelerator (Sordina, Padova, Italy) delivering an electron beam with energies ranging from 4 to 10 $\mathrm{MeV}$. The collimation of the beam was achieved by a harddocking system, consisting of 4-, 5-, or 6-cm diameter perspex applicators, using electron energy of 6,8 and $10 \mathrm{MeV}$, respectively. A shielding disk, made from lead and aluminum, was inserted between the residual breast gland and the pectoral muscle in order to limit thoracic wall irradiation.

In vivo dosimetry was performed for each treatment with a mobile MOSFET system (Best Medical; Ottawa, Ontario, Canada) using a micro MOSFET 502-RDM inserted into a closed-end $6 \mathrm{Fr}$ brachytherapy catheter positioned below the disk, in the middle of the irradiation field (17).

Protection of the chest wall was guaranteed by the absorptive properties of the lead and the aluminum and by the 9 -mm distance created by the disk (18).

The total dose was delivered in two consecutive steps, in each of which half of the prescribed dose was given. This two-step procedure allowed the dose delivered at the first step to be controlled, and individually corrected at the second step.

The primary study endpoint was 5-year local relapse-free survival (LRFS) from IORT treatment, evaluated by annual mammograms and clinical examination, secondary endpoints were overall survival (OS) and evaluation of subcutaneous tissue toxicity. The differences between the 18 Gy and 21 Gy groups were analyzed using the chi-square test or Fisher's exact test for categorical variables and the Student $t$-test for continuous variables.

\section{Results}

The median follow-up was 91 months (range=16-104 months). Sixty-five patients (pT1a\b, pN0\mic, pMx, G1-G3) received $18 \mathrm{~Gy}$ and 134 (pT1c\2, pN0\mic, pMx, G1-G3) received $21 \mathrm{~Gy}$.

Seven patients presented local relapse, two $(3 \%)$ in the 18 Gy arm and five $(3.7 \%)$ in the 21 Gy arm.
Table I. Patient selection for enrollment in the intraoperative radiotherapy with electrons procedure.

\begin{tabular}{ll}
\hline Parameter & Accrual favorable criteria \\
\hline Age & $>45$ Years \\
Histology & Invasive not lobular carcinoma \\
& No extensive $(<25 \%)$ intraductal component \\
Tumor size assessment & $\leq 2.5 \mathrm{~cm}$ \\
Surgical margins & Negative $(>5 \mathrm{~mm})$ \\
Follow-up & Patient's availability \\
Radiological examinations & Patient's availability \\
Informed consent & Obtained \\
\hline
\end{tabular}

The cumulative 5-year LRFS and OS for the whole cohort were $96.5 \%$ and $96 \%$, respectively. No significant difference in LRFS and OS was detected in the $18 \mathrm{~Gy}-$ treated arm versus the 21 Gy-treated arm: at 5 years: $96.9 \%$ vs. $96.3 \% p=0.72$; and $96.9 \%$ vs. $95.5 p=0.82$, respectively (Figures 1 and 2).

At final histological examination, 176 patients presented invasive ductal carcinoma and 23 patients other histology (none invasive lobular carcinoma or ductal carcinoma in situ) (Table II).

With regards to histology (invasive ductal carcinoma $v s$. other) and molecular subtype [luminal A, luminal B, human epidermal growth factor receptor 2 overexpression $\left(\mathrm{HER} 2^{+}\right.$), basal-like], no significant differences were detected between the two groups.

With regards to toxicity, in nine patients, three $(4.6 \%)$ in the $18 \mathrm{~Gy}$-treated arm and six (4.4\%) in the $21 \mathrm{~Gy}$-treated arm, breast ultrasound during follow-up showed liponecrosis.

According to the Modified Late Effects Normal Tissue Task Force-Subjective, Objective, Management and Analytic (LENT-SOMA) scoring system (19), long-term follow-up of the subcutaneous tissue effects showed two patients $(3.07 \%)$ had G2 fibrosis, 11 (16.92\%) G1 and 52 (80\%) had no fibrosis in the 18 Gy-treated group; in the other group treated with $21 \mathrm{~Gy}$, six patients $(4.47 \%)$ had $\mathrm{G} 2$ fibrosis, 24 (17.91\%) G1 and 104 (77.61\%) had no fibrosis (Figure 3).

\section{Discussion}

Several randomized trials and large multi-institutional studies suggest that is fundamental to follow guidelines in order to better select a subset of women that are suitable candidates for IORT treatment $(8,9,17,20)$. According to the statement in the American Society for Radiation Oncology (ASTRO) consensus guideline, updated in 2017, it was established that IORT with electron use should be limited to women who otherwise meet 'suitable' criteria for partial breast irradiation (21). 


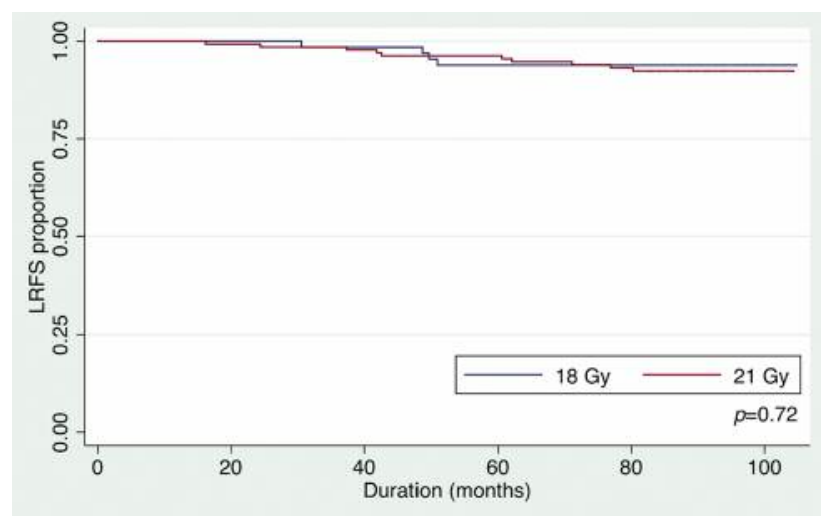

Figure 1. Local recurrence-free survival according to intraoperative radiotherapy dose.

Table II. Patient characteristics according to dose of intraoperative radiotherapy with electrons (IORT).

\begin{tabular}{|c|c|c|c|}
\hline \multirow[b]{2}{*}{ Characteristic } & \multicolumn{2}{|c|}{ IORT dose } & \multirow[b]{2}{*}{$p$-Value } \\
\hline & $18 \mathrm{~Gy}$ & $21 \mathrm{~Gy}$ & \\
\hline No. of patients & 65 & 134 & \\
\hline Mean age (SD), years & $66.1(9.3)$ & $67.0(11.0)$ & $0.551^{\mathrm{a}}$ \\
\hline \multicolumn{4}{|l|}{ T-Stage, $\mathrm{n}$} \\
\hline $\mathrm{T} 1 \mathrm{a}$ & 8 & 0 & $<0.001^{\mathrm{b}}$ \\
\hline $\mathrm{T} 1 \mathrm{~b}$ & 57 & 0 & \\
\hline $\mathrm{T} 1 \mathrm{c}$ & 0 & 121 & \\
\hline $\mathrm{T} 2$ & 0 & 13 & \\
\hline \multicolumn{4}{|l|}{ Grading, $\mathrm{n}$} \\
\hline G1 & 13 & 21 & $0.070^{\mathrm{b}}$ \\
\hline $\mathrm{G} 2$ & 48 & 89 & \\
\hline G3 & 4 & 24 & \\
\hline \multicolumn{4}{|l|}{ Histology, n } \\
\hline DCI & 56 & 120 & $0.494^{c}$ \\
\hline Other & 9 & 14 & \\
\hline
\end{tabular}

DCI: Ductal carcinoma in situ. aStudent's $t$-test, bisher's exact test, ${ }^{\mathrm{c}}$ Chi-square test.

Vaidya et al. in the TARGIT-A trial, a randomized, noninferiority study, enrolled 3451 women older than 45 years from 33 international centers from 10 countries (UK, USA, Germany, Italy, France, Poland, Switzerland, Denmark, Canada and Australia). Patients were randomly assigned in a 1:1 ratio to receive targeted IORT with a dose of $20 \mathrm{~Gy}$ or WBI with a dose of 40-56 Gy with or without a boost (8). This trial demonstrated that the targeted IORT approach is non-inferior regarding its efficacy in controlling local recurrence in selected patients.

Veronesi et al. at the European Institute of Oncology (Milan, Italy) conducted a randomized trial comparing local

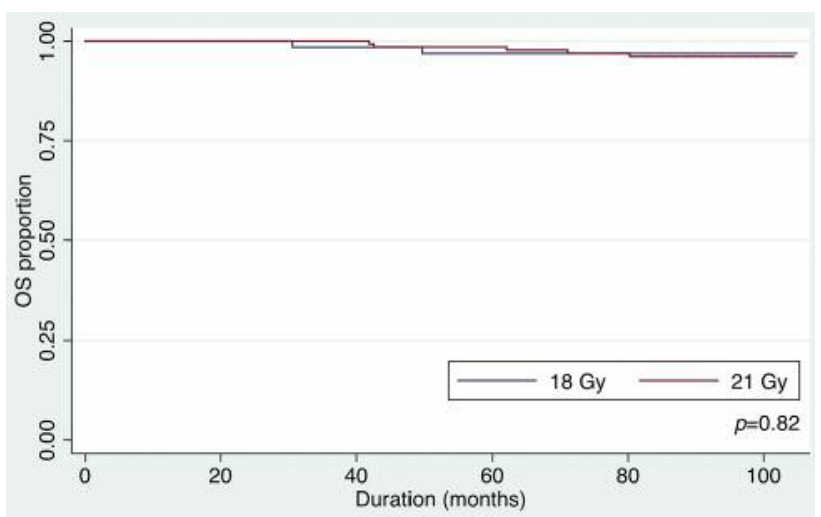

Figure 2. Overall survival according to intraoperative radiotherapy dose.

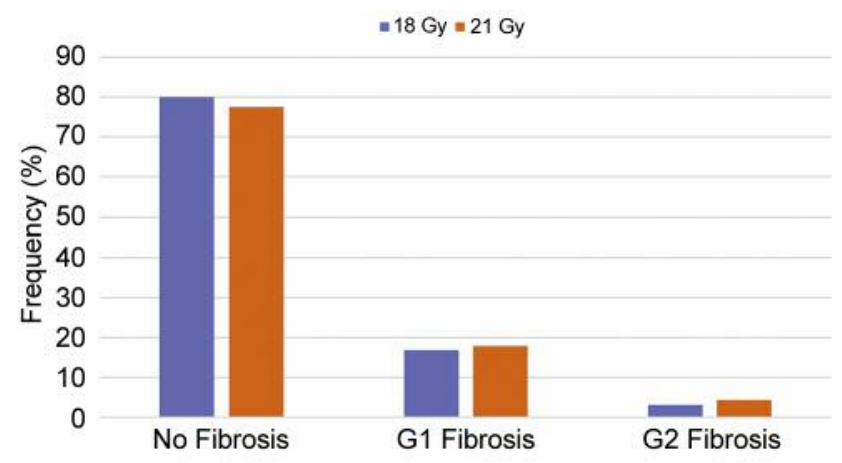

Figure 3. Assessment of late toxicity (fibrosis) using the modified LENTSOMA scale (19).

recurrence and overall survival in patients treated by electron IORT (ELIOT) versus postoperative external radiotherapy. A total of 654 women were assigned to the external radiotherapy group (50 Gy with $10 \mathrm{~Gy}$ boost) and 651 to the ELIOT group (21 Gy with 6-9 MeV electrons). The outcomes were assessed at 5 years from the end of the accrual (median follow-up of 5.8 years). The conclusion of this randomized analysis was that IORT with electrons should be restricted to suitable patients due to an increased risk of ipsilateral breast tumor recurrences (4.4 vs. $0.4 \%$, $p=0.0001)(9)$.

Guenzi et al. in a recently published study retrospectively analyzed 470 patients with early breast cancer, comparing treatment with IORT and hypofractionated WBI. Local relapse was observed in $3.4 \%$ (8/235) among patients treated with IORT and $0.42 \%(1 / 235)$ among those treated with hypofractionated WBI $(p=0.0192)$, these results also suggested that rigorous patient selection is needed (17). 
Furthermore, Leonardi et al. conducted a study focused on the role of histology in patients with early breast cancer treated by exclusive IORT. The comparison of treatment outcome between 252 patients affected by invasive lobular carcinoma and 1,921 patients with ductal carcinoma highlighted a higher incidence of recurrence in patients with lobular carcinoma than in those with ductal carcinoma (22).

However, in conclusion, all the different trials focusing on partial breast irradiation over the past 10 years have shown that in properly selected patients with breast cancer, APBI and WBI had similar outcomes. In the last ASTRO consensus statement published in 2017, the suitability criteria for APBI were updated as follow: age $\geq 50$ years, pTis or T1: low to intermediate nuclear grade, tumor size $\leq 2.5 \mathrm{~cm}$, resected with negative margins at $\geq 3 \mathrm{~mm}(21)$.

As regards the single radiation dose, several studies were conducted to establish which is the most suitable, effective and safe. Veronesi et al. tested different radiation dose levels: 10, 15 Gy (as a boost) 17, 19 and $21 \mathrm{~Gy}$ (as an exclusive dose) and stated as a standard of care the $21 \mathrm{~Gy}$ dose level since it was found to be safe without major acute side-effects (23).

In our trial, we explored $18 \mathrm{~Gy}$ as a single dose as a deescalated level for very early tumors with a size of less than $1 \mathrm{~cm}$ to assess the toxicity rate as well as long-term disease control. Biologically, in cases with early tumor, residual microscopic cancer cells after surgery may be well oxygenated, less proliferative and less aggressive (G3: 6\% in the 18 Gy-treated group vs. $18 \%$ in the $21 \mathrm{~Gy}$ treated group). Our results confirm that a lower dose of IORT for selected breast tumors may be as safe and effective as the 21 Gy dose: as observed in our research, potential late toxicity may be low. Although $21 \mathrm{~Gy}$ remains the more common dose for exclusive IORT with electrons in breast cancer, from our data no differences for the lower 18 Gy dose emerge. Delivering less radiation dose to women with breast cancer may be of radioprotective benefit with minor risk of long-term radiation-induced effects.

We report that IORT with a single dose of 18 Gy may be considered as an option for breast tumors smaller than $1 \mathrm{~cm}$. This suggestion emerges from the evidence that the lower dose of $18 \mathrm{~Gy}$, in one fraction, appeared to be able to achieve excellent results in terms of local toxicity, cosmetics and local control in selected cases with early breast cancer. A longer follow-up and further trials are necessary to confirm these results.

\section{Conflicts of Interest}

There is no conflict of interest to disclose.

\section{References}

1 Clarke M, Collins R, Darby S, Davies C, Elphinstone P, Evans V, Godwin J, Gray R, Hicks C, James S, MacKinnon E, McGale P, McHugh T, Peto R, Taylor C, Wang Y and Early Breast Cancer Trialists' Collaborative Group (EBCTCG): Effects of radiotherapy and of differences in the extent of surgery for early breast cancer on local recurrence and 15-year survival: An overview of the randomised trials. Lancet 366 : 2087-2106, 2005.

2 Limbergen E van, Bogaert W van den, Schueren E van der and Rijnders A: Tumor excision and radiotherapy as primary treatment of breast cancer. Analysis of patient and treatment parameters and local control. Radiother Oncol 8: 1-9, 1987.

3 Holland R, Veling SH, Mravunac $M$ and Hendriks JH: Histologic multifocality of Tis, T1-2 breast carcinomas. Implications for clinical trials of breast-conserving surgery. Cancer 56: 979-990, 1985.

4 Njeh CF, Saunders MW and Langton CM: Accelerated partial breast irradiation (APBI): A review of available techniques. Radiat Oncol 5: 90, 2010.

5 Mannino $\mathrm{M}$ and Yarnold J: Accelerated partial breast irradiation trials: Diversity in rationale and design. Radiother Oncol 91: 1622, 2009.

6 Coles CE, Griffin CL, Kirby AM, Titley J, Agrawal RK, Alhasso A, Bhattacharya IS, Brunt AM, Ciurlionis L, Chan C, Donovan EM, Emson MA, Harnett AN, Haviland JS, Hopwood P, Jefford ML, Kaggwa R, Sawyer EJ, Syndikus I, Tsang YM, Wheatley DA, Wilcox M, Yarnold JR and Bliss JM: Partial-breast radiotherapy after breast conservation surgery for patients with early breast cancer (UK IMPORT LOW trial): 5-year results from a multicentre, randomised, controlled, phase 3, noninferiority trial. Lancet 390: 1048-1060, 2017.

7 Guenzi M, Fozza A, Blandino G, Timon G, Belgioia L, Vidano G, Cavagnetto F, Gusinu M, Agostinelli S, Garelli S, Zeverino M, Taccini G and Corvò R: Focus on the actual clinical target volume irradiated with intraoperative radiotherapy for breast cancer. Anticancer Res 32: 4945-4950, 2012.

8 Vaidya JS, Joseph DJ, Tobias JS, Bulsara M, Wenz F, Saunders C, Alvarado M, Flyger HL, Massarut S, Eiermann W, Keshtgar M, Dewar J, Kraus-Tiefenbacher U, Sütterlin M, Esserman L, Holtveg HMR, Roncadin M, Pigorsch S, Metaxas M, Falzon M, Matthews A, Corica T, Williams NR and Baum M: Targeted intraoperative radiotherapy versus whole-breast radiotherapy for breast cancer (TARGIT-A trial): An international, prospective, randomised, non-inferiority phase 3 trial. Lancet 376: 91-102, 2010.

9 Veronesi U, Orecchia R, Maisonneuve P, Viale G, Rotmensz N, Sangalli C, Luini A, Veronesi P, Galimberti V, Zurrida S, Leonardi MC, Lazzari R, Cattani F, Gentilini O, Intra M, Caldarella $\mathrm{P}$ and Ballardini B: Intraoperative radiotherapy versus external radiotherapy for early breast cancer (ELIOT): A randomised controlled equivalence trial. Lancet Oncol 14: 12691277, 2013.

10 Esposito E and Douek M: Update on intraoperative radiotherapy: New challenges and issues. E Cancer Med Sci 12: 793, 2018.

11 Orecchia R, Ciocca M, Lazzari R, Garibaldi C, Leonardi MC, Luini A, Intra M, Gatti G, Veronesi P, Petit JI and Veronesi U: Intraoperative radiation therapy with electrons (ELIOT) in earlystage breast cancer. Breast 12: 483-490, 2003. 
12 Bhandari T, Babaran W, Forouzannia A, Williams V, Harness J, Carpenter M, Gobran M, Khanijou R, Wagman B, Ash R and Wagman LD: A prospective phase I comparison of toxicity and cosmesis outcomes of single-fraction IORT and hypofractionated radiotherapy with IORT boost in early-stage breast cancer. Brachytherapy 16: 1232-1238.e2, 2017.

13 Harris EER and Small W: Intraoperative radiotherapy for breast cancer. Front Oncol 7: 317, 2017.

14 Hanna GG and Kirby AM: Intraoperative radiotherapy in early stage breast cancer: Potential indications and evidence to date. Br J Radiol 88: 20140686, 2015.

15 Astrahan M: Some implications of linear-quadratic-linear radiation dose-response with regard to hypofractionation. Med Phys 35: 4161-4172, 2008.

16 Guenzi M, Vagge S, Azinwi NC, D’Alonzo A, Belgioia L, Garelli S, Gusinu M and Corvò R: A biologically competitive 21 days hypofractionation scheme with weekly concomitant boost in breast cancer radiotherapy feasibility acute sub-acute and short-term late effects. Radiat Oncol Lond Engl 5: 111, 2010.

17 Guenzi M, Bonzano E, Corvò R, Merolla F, Pastorino A, Cavagnetto F, Garelli S, Cutolo CA, Friedman D and Belgioia $\mathrm{L}$ : Comparison of local recurrence among early breast cancer patients treated with electron intraoperative radiotherapy $v s$. hypofractionated photon radiotherapy an observational study. Front Oncol 8: 207, 2018.

18 Intra M, Gatti G, Luini A, Galimberti V, Veronesi P, Zurrida S, Frasson A, Ciocca M, Orecchia R and Veronesi U: Surgical technique of intraoperative radiotherapy in conservative treatment of limited-stage breast cancer. Arch Surg 137: 737-740, 2002.

19 LENT SOMA tables. Radiother Oncol J Eur Soc Ther Radiol Oncol 35: 17-60, 1995.
20 Smith BD, Arthur DW, Buchholz TA, Haffty BG, Hahn CA, Hardenbergh PH, Julian TB, Marks LB, Todor DA, Vicini FA, Whelan TJ, White J, Wo JY and Harris JR: Accelerated partial breast irradiation consensus statement from the American Society for Radiation Oncology (ASTRO). Int J Radiat Oncol Biol Phys 74: 987-1001, 2009.

21 Correa C, Harris EE, Leonardi MC, Smith BD, Taghian AG, Thompson AM, White J and Harris JR: Accelerated partial breast irradiation: Executive Summary for the update of an ASTRO Evidence-Based Consensus Statement. Pract Radiat Oncol 7: 73-79, 2017.

22 Leonardi MC, Maisonneuve P, Mastropasqua MG, Cattani F, Fanetti G, Morra A, Lazzari R, Bazzani F, Caputo M, Rotmensz N, Gerardi MA, Ricotti R, Enrica Galimberti V, Veronesi P, Dicuonzo S, Viale G, Jereczek-Fossa BA and Orecchia R: Comparison of treatment outcome between invasive lobular and ductal carcinomas in patients receiving partial breast irradiation with intraoperative electrons. Int J Radiat Oncol Biol Phys 99: 173-181, 2017.

23 Veronesi U, Orecchia R, Luini A, Gatti G, Intra M, Zurrida S, Ivaldi G, Tosi G, Ciocca M, Tosoni A and De Lucia F: A preliminary report of intraoperative radiotherapy (IORT) in limited-stage breast cancers that are conservatively treated. Eur J Cancer 37: 2178-2183, 2001.

Received July 10, 2018

Revised July 27, 2018

Accepted August 7, 2018 